RESEARCH PAPER

\title{
Social movements and human rights rhetoric in tobacco control
}

\author{
P D Jacobson, A Banerjee
}

Tobacco Control 2005;14(Suppl II):ii45-ii49. doi: 10.1136/tc.2004.008029

After achieving breathtaking successes in securing state and local restrictions on smoking in public places and restricting youth access to tobacco products, the tobacco movement faces difficult decisions on its future strategic directions. The thesis of this article is that the tobacco control movement is at a point of needing to secure its recent successes and avoiding any public retrenchment. To do so requires rethinking the movement's strategic direction. We use the familiar trans-theoretical model of change to describe where the movement is currently and the threats it faces. The new tobacco control strategy should encompass a focus on voluntary non-smoking strategies, use human rights rhetoric to its advantage, and strengthen the public health voice to be more effective in political battles. In developing a new strategy, tobacco control advocates need to build a social movement based on a more forceful public health voice, along with the strategic use of human rights rhetoric, to focus on the power of voluntary non-smoking efforts. Using human rights rhetoric can help frame the movement in ways that have traditionally appealed to the American public. Perhaps more importantly, doing so can help infuse the tobacco control movement with a broader sense of purpose and mission.

See end of article for authors' affiliations

Correspondence to: Professor Peter D Jacobson, JD, MPH, Center for Law and Health Systems, University of Michigan School of Public Health Ann Arbor, Ml 481092029, USA; pdi@umich. edu t is exceedingly difficult to sustain an effective social movement in the USA. Take the environmental movement as an example. After achieving breathtaking successes in its initial years, such as providing the political impetus for the enactment of clean air and clean water acts, the political momentum has shifted and the movement has stalled. ${ }^{*}$ The same might be said for the women's movement. Despite early successes, there were some notable political failures, including the inability to enact an equal rights amendment. Despite sound economic gains, the "glass ceiling" remains.

The thesis of this article is that the tobacco control movement faces similar issues regarding forward momentum and the need to determine its strategy for the future. That strategy should

* Consider, for instance, the tepid political support for the Kyoto Treaty. Even if Al Gore had been elected in 2000, it is unlikely that the Senate would have ratified the Kyoto Protocol encompass a focus on voluntary non-smoking policies, using human rights rhetoric to its advantage, and on strengthening its public health voice to be more effective in political battles. As several advocates have noted, tobacco control will not be an effective political force until the movement defeats a political candidate for opposing tobacco control efforts.

At the outset, it is important to note that this article is designed to provoke and stimulate thinking and discussion among tobacco control advocates about the future. It is not intended to be an empirically based analysis. Equally important, we do not view the current position of the movement as being at a tipping point. Under no circumstances do we anticipate major retrenchment. To the contrary, we firmly believe that the changes in social norms secured in recent years are unlikely to revert back to tobacco's glamour years, and we expect that it will be very difficult for the tobacco industry to unravel the regulatory structure already in place. The industry's admission that its products cause harm when used as intended and its willingness to negotiate over the Food and Drug Administration's (FDA's) regulatory authority suggest that there is no immediate threat of retrenchment. That said, this is the time for the movement to devise a strategy for the future to build on the gains already achieved. Strengthening tobacco control as a social movement is crucial to sustaining successes and providing the impetus for difficult battles that lie ahead, such as the shape of FDA regulation over tobacco products.

\section{THREATS}

Over the past 20 years, the tobacco control movement has achieved extraordinary successes, arguably far beyond what anyone anticipated. Aside from the enactment of once unthinkable restrictions on smoking in public places, including virtually no smoking in public places in California and New York City, the movement is responsible for changing the nation's social norms regarding tobacco use. Even in areas where strong anti-smoking laws have not been enacted, smokers are on the defensive and the cultural norm no longer favours public tobacco use. The spread of voluntary restrictions on tobacco use suggests how much the social norms have changed. And the fact that juries now routinely award damages to individual smokers is a remarkable turnaround from the fact that the tobacco industry had never paid to resolve litigation until the mid to late 1990s.

Yet there are a number of reasons to be concerned that the tobacco control movement 
could share the fate of other social movements in being unable to build on its successes, even if the past victories are likely to be sustained far into the future. The threats are both internal and external to the movement.

First, there is an inevitable tendency to say "we've won"there are other battles to confront. Volunteers are particularly susceptible to this reaction. One study found that tobacco control coalitions had difficulty sustaining members' interest in the less exciting work of implementing and enforcing tobacco control laws. ${ }^{1}$ The study also found that politicians' interest waned after enacting the law. Thus, the perception of success may well encourage tobacco coalition volunteers to join other social movements instead of continuing to pursue tobacco control objectives.

Second, the tobacco control movement has become highly professionalised and institutionalised. $†$ In many respects, this is a profoundly positive development. Without the funds and lobbying muscle from the voluntary associations, it is unlikely that state anti-smoking laws would either be as prevalent or as strong as they are now. ${ }^{3}$ Equally important, groups that now comprise the tobacco control infrastructure, such as the American Legacy Foundation and the Campaign for Tobacco-Free Kids, have kept tobacco control on the policy agenda and have contributed to steadily reducing tobacco consumption rates among both children and adults.

At the same time, the shift to a professional cadre may well "crowd out" the volunteers needed to sustain the movement. If volunteers think that capable professionals will sustain the movement or, worse still, that the professionals will not listen to the volunteers, it is likely that they will migrate to other social movements. The danger is that national, professional organisations will eclipse the grass roots efforts. Likewise, the success of the litigation against the tobacco industry may encourage many to "leave it to the lawyers". Litigation might detract from other policy efforts if the public perceives that the problem has been "solved" through litigation, in part through the allure of money. ${ }^{4}$

A related concern is that a professional tobacco control movement is dependent on continued funding rather than grass roots organising. For instance, the American Legacy Foundation's future financial security is tied to a complicated funding formula dependent on tobacco consumption patterns. Other professional organisations are dependent on continued foundation funding, which is always subject to changing strategies and new leadership. The Robert Wood Johnson Foundation has been a strong supporter of tobacco control research and strategies, and will continue to be, but at an increasingly reduced level. The Foundation is shifting priority to reducing the nation's obesity epidemic.

Third, the tobacco control movement, like most public health movements, is subject to fragmentation. One need only review the difficulties tobacco control advocates had in speaking with one voice regarding the McCain legislation in 1996 to realise that difficult questions about harm reduction strategies could well fragment the movement if FDA gains regulatory jurisdiction over tobacco products. ${ }^{5}$

Finally, tobacco control's opponents are not necessarily accepting the status quo. Indeed, libertarians and political conservatives continue to oppose governmental intervention (that is, tobacco control laws) in the marketplace and argue strenuously that the tobacco control movement has overreached. ${ }^{6}$ While substantial retrenchment seems unlikely, it will be difficult to generate new successes without engendering a potential political backlash if additional laws are viewed

†This phenomenon is not unique to tobacco control, but characterises many of the social movements emerging from the 1960s and 1970s. For instance, the National Organization of Women became one of the most recognised and influential voices of the women's movement (Everett ${ }^{2}$ ). as too intrusive. At best, tobacco control advocates will be able to consolidate gains already achieved.

Another way of looking at these issues is to adapt the familiar trans-theoretical change model to conceptualise the tobacco control movement's evolution and its current status (table 1). Although the model is designed to explain individuals' internal decision making processes regarding addictive behaviours, we think it can be adapted to help explain tobacco control's historical context and to facilitate discussion of future directions. Extrapolating from this model helps identify the role that social movements and human rights rhetoric might play in the dynamics of continued social change.

Based on table 1 , it seems clear that the tobacco control movement can be characterised as falling in the "Maintenance" stage. After an extraordinary period of growth and success in the "Action" stage during the 1990s, tobacco control is arguably in a period of consolidating recent gains. ${ }^{8}$ Our concern, however, is that the tobacco control movement could easily migrate into the "Relapse" stage, where some of the successes could be in jeopardy and where continued progress is difficult.

If this model is a plausible reflection of the tobacco movement's evolution, three implications follow. First, it is important not to lose sight of strategies that will maintain and consolidate advances made during the action stage. One could in fact argue that the maintenance stage offers a "breathing period" following the frenetic activity of the 1990s to reconsider ongoing efforts, such as media and political strategies. Far from being thought of as stasis, the maintenance stage is an opportunity to institutionalise gains that will resist retrenchment, and to develop strategies to avoid relapse without the pressure and controversy of moving into future debates. For example, tobacco control advocates can use the current respite to prepare strategies for potential FDA regulation.

Second, it suggests that the trajectory toward further advances is hardly guaranteed. If relapse (defined as losing the gains already won or losing the grass roots volunteer base) is a possibility, then identifying steps to minimise the probability of relapse should be an important aspect of the maintenance stage. Keeping the tobacco movement at the forefront of social consciousness should be a key goal of the maintenance phase.

And third, maintenance is the opportunity to begin thinking about developing a new tobacco control strategy. What are the next areas of focus and policy objectives? How should the movement be organised to achieve those goals?

\section{DEVELOPING A NEW STRATEGY}

In developing a new strategy, tobacco control advocacy needs to build a social movement based on a more forceful public health voice (perhaps through human rights rhetoric) that will put political pressure on legislators to enact strong tobacco control laws, will continue to place the tobacco industry on the defensive, and will not be susceptible to industry co-opting. In addition, tobacco control advocates have underestimated the power of voluntary non-smoking efforts. At this point in the evolution of tobacco control advocacy, the focus should be on taking advantage of changes in social norms to encourage more businesses to voluntarily adopt no smoking policies regardless of current legal requirements. A value of this strategy is that it effectively co-opts the conservative and libertarian critique about the dangers of moral crusades. By using advocacy to persuade the market to advance tobacco control objectives, libertarians can hardly object to the expression of consumer preferences. 
Table 1 Stages of change model/system's change process ${ }^{7}$

\begin{tabular}{|c|c|c|}
\hline Stage in trans-theoretical model of change & Patient stage & Tobacco as social movement \\
\hline Pre-contemplation & $\begin{array}{l}\text { Not considering change. Resigned, lack } \\
\text { of control over situation. Denial (situation } \\
\text { and consequences) }\end{array}$ & $\begin{array}{l}1884-1914 \\
\text { Consolidation of tobacco industry; tobacco control laws } \\
\text { repealed; government support during second world war; } \\
\text { promotion in Hollywood }\end{array}$ \\
\hline Contemplation & $\begin{array}{l}\text { Weighing benefits and costs of behaviour, } \\
\text { proposed change }\end{array}$ & $\begin{array}{l}\text { 1950-1964 } \\
\text { Increasing concerns in medical literature re correlation } \\
\text { between cancer and tobacco }\end{array}$ \\
\hline Preparation & Experimenting with small changes & $\begin{array}{l}\text { 1960-mid 1980s } \\
\text { Increased literature; initial policy proceedings (Minnesota); } \\
\text { tobacco industry on the defensive }\end{array}$ \\
\hline Action & Taking a definitive action to change & $\begin{array}{l}\text { Late 1980s-current } \\
\text { Voluntary efforts of independent, private institutions; } \\
\text { successful legislative efforts; changing social norms; } \\
\text { litigation successes }\end{array}$ \\
\hline Maintenance & Maintaining new behaviour over time & $\begin{array}{l}\text { Current } \\
\text { Social reinforcement; retain political backing; } \\
\text { consolidation of successes; implementation and } \\
\text { enforcement. }\end{array}$ \\
\hline Relapse & $\begin{array}{l}\text { Experiencing normal part of process of } \\
\text { change. Usually feels demoralised }\end{array}$ & $\begin{array}{l}\text { Future } \\
\text { Potential setbacks; change in political climate; movement } \\
\text { fragmentation; change in voluntary movement effort }\end{array}$ \\
\hline
\end{tabular}

\section{Social movements}

In our view, the key to future tobacco control success lies in maintaining, at a minimum, and expanding, if possible, tobacco control as a broadly based social movement.9 As important as it is to maintain and expand the institutional/ professional tobacco control structure, it is equally important to nurture an active grass roots, volunteer tobacco control coalition. The former brings visibility, political clout, and fundraising capacity; the latter reinforces social norms, establishes a stable movement foundation, and facilitates change at the local and state levels. Success at both levels is needed to avoid the relapse stage.

The volunteer effort (as distinct from the role of professionals) involves three intertwined questions. How can volunteers be mobilised to undertake the tedious and time consuming work of building on past successes? What should the local coalition's goals be? What will the relationship be between coalitions and professional tobacco control advocates?

\section{Mobilisation}

One way to mobilise volunteers is to develop better linkages with other local coalitions within and across states. Within states, local and statewide coalitions need to establish mechanisms to meet and coordinate strategy. These efforts must be ongoing and not relegated to crisis situations. In fact, one goal of closer coordination is to anticipate and avoid crisis situations. Across states, coalitions should consider forming regional organisations.

While resources for doing so are admittedly limited, regional organisations serve numerous beneficial functions. First, they facilitate the diffusion of laws and successful strategies across regional boundaries. Even in the electronic age, sharing information and strategies at conferences remains an effective mechanism for achieving social goals and deciding how best to frame these goals. We know that how an issue is framed is critical to public health outcomes. ${ }^{10}$ Yet framing is a dynamic challenge, changing in unpredictable ways. Routine regional meetings allow the collective movement to define and frame the desired importance of competing issues and determining how and to whom the issue or message should be presented. In short, regional meetings help local coalitions make effective use of scarce resources.
Second, organising regionally provides momentum that can be translated into greater political successes. Regional organisations can help provide the missing public health voice that leads to political gains. Third, they facilitate local mobilisation by bringing together a critical mass. It is hard to retain volunteers if they are detached from like-minded individuals and coalitions. Regional meetings invoke a shared sense of purpose, renew the movement's energy, and encourage advocates to remain engaged.

It seems counter-intuitive not to focus on resource mobilisation as the key to social movement success and survival. Yet a study of the social movement against drunk driving supports our analysis. The authors compared the differential success of two organisations to mobilise communities against drunk driving. They concluded that success lay not in the ability to solicit revenue, but rather in maximising volunteer input, satisfactorily involving local leadership, and coordinating activity between the local and state levels. ${ }^{11}$

\section{Voluntary change}

Aside from maintaining a stable foundation for the tobacco control movement, we argue that local coalitions should focus on advocating and facilitating the adoption of voluntary non-smoking policies. This, too, may seem counter-intuitive in view of the organising propensities of engaging in the legislative process (at either the state or local level). To be sure, the allure of engaging in the political process is an effective strategy for attracting new members. The problem is that once the legislative battles are over, there is little incentive for them to remain active. In contrast, organising around securing voluntary no smoking policies attracts members who are likely to remain engaged over the long term and may lead to even more significant changes in tobacco control policy than attainable through the legislative process.

We see three advantages to a strategy focused on advocacy for adopting private self regulation (that is, voluntary change). One is that it provides an organising principle for a local coalition. As with the legislative process, there are measurable goals that can be achieved. For example, the coalition can track the number of private establishments adopting non-smoking policies, produce materials identifying non-smoking businesses, and monitor the number of times members encourage businesses to change their policies. A second advantage is that it both reinforces and extends social 
norms favouring restrictions on smoking in public places Those voluntarily adopting no smoking policies are likely to enforce them vigorously, hence avoiding the problem of lax governmental enforcement. ${ }^{12}$ And third, it is a market based approach, which deprives opponents of tobacco control laws one of their primary strategies in attacking non-smoking policies. Libertarians can hardly complain if local coalitions use effective community based organising strategies to encourage social changes in local markets. ${ }^{13}$

\section{Relations with professionals}

Since professionals will be working on strategies that are much broader than voluntary change, how should grass roots activists and professionals interact? For now, we believe that grassroots coalitions have a comparative advantage in organising volunteer non-smoking efforts, while professionals focus on the entire range of tobacco control regulation and cessation. Certainly, coalitions should be willing to switch their focus to respond to opportunities that the professionals identify. For instance, if the professionals target a state or locality for a tobacco control law, the coalition should be flexible enough to lend support.

As a general proposition, coalitions should work closely with professionals to identify other volunteer activities that coalitions can organise. Coalitions can effectively engage in monitoring compliance with non-smoking laws, encourage no smoking in private homes, and encourage participation in smoking cessation programmes. Even if the effort to convince businesses to go smoke-free is wildly successful, coalitions will still have considerable opportunities to participate in tobacco control activities.

\section{Human rights rhetoric}

An intriguing strategy that is gaining considerable scholarly attention is the use of human rights rhetoric. In previous work, one of the authors (PDJ) argued that the use of human rights rhetoric to justify public health intervention is susceptible to being co-opted by industry opponents of public health initiatives. ${ }^{14} \mathrm{~A}$ focus on human rights rhetoric as a primary strategy will not resonate with politicians, will be confusing to many tobacco control advocates, and will result in endless definitional and practical difficulties. At the same time, the language of human rights can be an effective complement to the social movement approach suggested above.

In the USA, framing policy choices with a moral dimension makes a difference. ${ }^{15}$ For example, one can argue that welfare reform occurred when proponents of change effectively argued that welfare was a moral failure because it encourages dependency. Before that, the disdain for "welfare queens" may have been politically effective, but was ineffective in changing social policy. In the end, the combined pragmatic and moral arguments overwhelmed welfare's defenders.

A similar but even more powerful example drove the women's movement. Women's suffrage was born in human rights rhetoric, but did not become a reality until combined with politically pragmatic considerations. For women's suffrage, the first such dictum occurred in 1791 with Olympe de Gouge's The Rights of Women, where she declares "...[a] woman is born free and lives equal to man in her rights" ${ }^{16}$ In the USA, raising social consciousness occurred through suffragist meetings, treatises, and primarily through political and judicial avenues. The movement occurred in spurts and certainly faced many setbacks. But as a whole, the women's movement moved forward through the transtheoretical change processes outlined earlier. State by state, the movement grew in force; partial suffrage was granted in New Jersey eventually leading to full suffrage in Wyoming in 1890.
The movement had its beginnings when Wyoming women demanded the right to vote when the territory was officially organised. ${ }^{17}$ Julia Bright persuaded her husband, the president of the territorial council, to introduce a suffrage bill to the council, which functioned as the upper house of territorial legislative bodies. As his best argument, William Bright said that making Wyoming unique in this respect would "attract attention to the...territory more effectually than anything else". His second argument was not based so much on principle as on partisanship. Because the governor said he would veto a suffrage bill, Bright encouraged Democrats to vote for it "to show that they were in favor of liberal measures while the Republican governor and the Republican party were opposed". After the bill passed, Bright led its supporters in lobbying Governor Campbell to reverse himself on the promised veto. Many women sent letters, while other women lobbied him in person. He finally decided that "he did not want the responsibility of offending women...or of placing the Republican party in open hostility to a measure he saw might become a political force". He signed the bill, and thereby "drew down upon himself the bitter curses" of legislators who, hypocritically, had voted for it but actually were opposed. In the end, it was lobbying skills and political forces that drew legislative attention, not fundamental human rights arguments. The key is that this movement began in an entirely grassroots fashion, and that human rights rhetoric was used side-by-side with other methods to achieve desired social change.

A cautionary story about sole reliance on human rights rhetoric emerges from the environmental movement. Like the tobacco control movement, the environmental movement has generated enormous success, both in legislative achievements and in keeping environmental issues at the forefront of the domestic policy agenda. Arguably, the environmental movement relied on the same combination of rights rhetoric (the right to a clean environment and preserving the environment for future generations) and shrewd political organising as with the women's movement. Yet when advocates attempted to recast the movement as environmental justice (arguing that polluting firms or industries should not be permitted to locate in poor neighbourhoods because it amounts to environmental racism), the movement stalled. The environmental justice movement has had few successes. In fact, industries have co-opted the human rights rhetoric by arguing that local communities have the right to the jobs that come with industry location decisions.

In sum, human rights language can be an invaluable adjunct to a wide range of tobacco control activities. Using human rights rhetoric can help frame the movement in ways that have traditionally appealed to the American public. Perhaps more importantly, doing so can help infuse the tobacco control movement with a broader sense of purpose and mission. But there are too many problems for it to be the central organising principle of the tobacco control movement.

\section{Public health voice}

Regardless of the goals that tobacco control advocates determine should be pursued (that is, legislation or voluntary activity), we urge greater attention to developing a strong public health voice. By public health voice, we mean the presence of a defined public health message that can effectively articulate a rationale behind proposed public health initiatives.

Research has demonstrated that when the public health voice is strong, tobacco control initiatives have been successfully enacted. In California several local municipalities were successful in passing legislation in the face of opposition from smokers' rights groups and business and restaurant lobbies that opposed the measures. This can be contrasted 


\section{What this paper adds}

This article adapts the well known trans-theoretical model of individual behavioural change to the tobacco control movement. Doing so allows us to consider where the movement is now and the threats that it faces. It also suggests ways in which tobacco control advocates should think about future strategic directions.

Another new aspect of the paper is its focus on strengthening tobacco control as a social movement rather than relying on professional advocates. We also argue that the movement should shift its focus from legislative activity to securing voluntary non-smoking policies among local businesses.

with Florida where funding for a successful youth programme was reduced in large part because of the absence of public health advocates emphasising its importance. The media programme was eroded while the local public health advocates and health organisations offered no protests.

The limited research on gun control activities portrays a similar story. With the possible exception of California, which enacted significant gun control legislation that includes a ban on assault weapons and Saturday night specials, the public health voice remains distinctly secondary to industry opposition. Part of the problem is in how the public health voice has been articulated. Instead of providing a coherent overview of what the public health approach would entail, the message tends to be fragmented and compartmentalised, one issue at a time, without the benefit of a broader public health context. This does not allow the debate to be framed within a public health model that could provide policymakers with a political rationale for enacting legislation consistent with a public health strategy. In Illinois, for example, testimony from health care professionals helped shift the terms of the youth violence debate to include prevention. But legislators supporting the public health model complained that public health advocates were neither well organised nor presented a centralised, consistent message. By contrast, one observer argued that "The pro-gun voices are more organised and influential than the general, non-specific gun control efforts". ${ }^{18}$

It is certainly unfair to lay the burden of developing a coherent public health voice on the tobacco control movement. That is a collective failure among all public health advocates. But the tobacco control movement is sufficiently institutionalised and effective that tobacco control advocates are in a position to begin the process of articulating a coherent public health voice. At a minimum, doing so ought to be on the agenda. In fairness, the Campaign for Tobacco Free Kids has demonstrated a strong capacity for articulating and disseminating a powerful tobacco control voice, as has the Legacy Foundation through its very effective "Truth" campaign. Individual advocates have been effective in achieving significant increases in tobacco excise taxes at the state level. These very successes point the way toward the broader movement that is needed.

\section{CONCLUSION}

Inevitably, the tobacco control movement will face unpredictable challenges and move in unanticipated ways. As new battles, such as the appropriateness of harm reduction strategies, replace the past emphasis on enacting clean indoor air and youth tobacco laws, core values and goals need to guide the movement to avoid costly fragmentation. Strengthening the social movement that lies at the heart of the tobacco control movement is essential. Using human rights rhetoric is one strategy that can provide momentum and a sense of purpose to the movement. A strong social movement is imperative to resist or prevent erosion in the salience of tobacco control (that is, to prevent relapse) and to provide the political and economic support to achieve future goals.

\section{Authors' affiliations}

P D Jacobson, A Banerjee, University of Michigan School of Public Health, Ann Arbor, Michigan, USA

Competing interests: none declared

\section{REFERENCES}

1 Jacobson PD, Wasserman J. Tobacco control laws: implementation and enforcement. Journal of Health Politics, Policy and Law 1999;24:567-98.

2 Everett KD. Professionalization and protest: changes in the social movement sector. Social Forces 1992;70:957-75.

3 Jacobson PD, Wasserman J, Raube KR. The politics of anti-smoking legislation: lessons from six states. Journal of Health Politics, Policy and Law 1993;18:787-819.

4 Jacobson PD, Warner KE. Litigation and public health policy: the case of tobacco control. Journal of Health Politics, Policy and Law 1999;24:769-804. For a more favourable analysis of the litigation as public health policy strategy, see: Parmet WE, RA Daynard. The new public health litigation. Annu Rev Public Health 2000;21:437-54.

5 Pertschuk M. Smoke in their eyes: lessons in movement leadership from the tobacco wars. Nashville, Tennessee: Vanderbilt University Press, 2001.

6 Sullum J. For your own good: the anti-smoking crusade and the tyranny of public health. New York: The Free Press, 1998.

7 Miller WR, Rollnick S. Motivational interviewing: preparing people to change addictive behavior. New York: The Guilford Press, 1991.

8 Jacobson PD, Wasserman J, Anderson J. Historical overview of tobacco legislation and regulation. Journal of Social Issues 1997;53:75-95.

9 CA Nathanson. Social movements as catalysts for policy change: the case of smoking and guns. Journal of Health Politics, Policy and Law 1999;24:421-88

10 Snow DA, Benford RD. Master frames and cycles of protest. In: Morris AD, Mueller CM, eds. Frontiers in social movement theory. New Haven: Yale University Press, 1992:133-55.

11 McCarthy JD, Wolfson M. Resource mobilization by local social movement organizations: agency, strategy, and organization in the movement against drunk driving. American Sociological Review 1996;61:1070-88.

12 Jacobson PD, Wasserman J. Tobacco control laws: implementation and enforcement. Journal of Health Politics, Policy and Law 1999;24:567-98. The authors found that there is minimal enforcement of no-smoking laws, a problem likely to be common internationally.

13 Jacobson PD, Wu L. Clean indoor air restrictions: progress and promise. In: Rabin RL, Sugarman SS, eds. Regulating tobacco. New York: Oxford University Press, 2001:207-44.

14 Jacobson PD, Soliman S. Co-opting the health and human rights movement. Journal of Law, Medicine, and Ethics 2002;30:705-15. For a contrasting argument in the context of bioterrorism, see: Gostin LO. When terrorism threatens health: how far are limitations on human rights justified. Journal of Law, Medicine and Ethics 2003;31:524-28.

15 Morone J. Hellfire nation. New Haven: Yale University Press, 2003.

16 Johnson L. Olympe de Gouge and the rights of woman, http:// womenshistory.about.com/library/weekly/aa071099.htm, 1999.

17 Weatherford D. A history of the American suffragist movement. New York: The Moschovitis Group, Inc, 1998.

18 Wasserman J, Greenwood PG, Davis L, et al. The California Wellness Foundation's violence prevention initiative, the first five years: phase one evaluation. RAND, PM-945/1-6-TCWF, July, 1999. 